REgier, D., FARMER, M., RAE. D.. et al (1990) Comorbidity of mental disorders with alcohol and other drug abuse. Results from the epidemiologic catchment area study. Journal of the American Medical Association. 264. 2511-2518.

Ridgely. S.. Goldman, H. \& WillenBring, M. (1990) Barriers to the care of persons with dual diagnosis: organisational and financing issues. Schizophrenia Bulletin. 16. 123-131.

Robbins, L.. Heltzer. J., COTtLer. L., et al (1989) NIMH Diagnostic Interview Schedule: Version 11, Revised. St Louis, MO: Washington University.

SMITH, J. \& HUCKER, S. (1994) Schizophrenia and substance abuse. British Journal of Psychiatry. 165. 13-21.
WORLD HEalth ORGanization (1992) The Tenth Revision of the International Classification of Diseases and Related Health Problems (ICD-10). Geneva: WHO.

Steve Brown, Honorary Lecturer, Department of Psychiatry. University of Southampton, Royal South Hants Hospital, Southampton

Correspondence: Dr S. Brown, Wolston Park Hospital. Wacol 4076, Queensland, Australia

\title{
Review of College guidelines on high-dose neuroleptic use in a psychiatric intensive care unit
}

\author{
Hugh Jones, Rachel Jones, and James V. Lucey
}

\begin{abstract}
Aims and method Guidelines on high-dose antipsychotic medication contained in the Royal College of Psychiatrists consensus statement were examined in a prospective study of 73 patients admitted to a psychiatric intensive care unit (ICU).

Results The mean (s.d.) neuroleptic dose received was $884 \mathrm{mg}$ (667) chlorpromazine equivalence per day. Thirteen patients received more than $1200 \mathrm{mg}$ chlorpromazine equivalence per day during at least one week, although adopting measures advocated in the guidelines allowed a reduction in neuroleptic dose for 10 of these patients. Illness severity and a patient's past history were associated with neuroleptic use. Clinical implications Adherence to the College guidelines is thus possible on a psychiatric ICU.
\end{abstract}

The Royal College of Psychiatrists consensus statement on the use of high-dose antipsychotic medication (Thompson, 1994) considered situations where high-dose neuroleptic use was more likely, described the risks of their use, and offered suggestions as to alternative treatment strategies. Violent and aggressive behaviour is common in psychiatric ICUs (Walker \& Seifert, 1994), and such behaviour has been associated with the use of higher neuroleptic doses (Peralta et al, 1994). Thus applying College guidelines on such a unit may not be straightforward. One recent retrospective study recorded average doses of $2100 \mathrm{mg}$ chlorpromazine equivalence per day on a psychiatric ICU (Hillam \& Evans, 1996). This study prospectively recorded neuroleptic use in 73 patients admitted to a psychiatric ICU.

\section{The study}

The patient sample constituted of 73 consecutive admissions to a 15-bed psychiatric ICU, opened one month prior to the beginning of the study at Homerton Hospital, London, recruited between September 1995 and January 1996. There were 54 male and 19 female patients with a mean age of 32.8 years. The mean length of stay was 20 days.

Thirty-six patients had an ICD-10 (World Health Organization, 1992) diagnosis of schizophrenia/schizoaffective disorder, eight of an acute schizophrenia-like illness, 21 of bipolar disorder, four of a drug-induced illness, two of a personality disorder and two an organic illness.

For 16 patients this was their first admission and for 15 their second. Twenty-two patients had 
between two and five admissions and 20 patients had more than five previous.

Forty-seven patients $(64 \%)$ had a past history of violence. Twenty-two (30\%) patients had a history of damage to property only, $18(25 \%)$ a history of non-serious injury to people and 7 $(10 \%)$ a history of causing serious injury to people.

Patients were assessed within 48 hours of admission using the Brief Psychiatric Rating Scale (Overall \& Gorham 1962) by two ward doctors (H. J. and R. J.). Violent incidents were recorded prospectively using the Overt Aggression Scale (Yudofsky et al, 1986). Neuroleptic use was calculated in milligram chlorpromazine equivalents (Rey et al, 1989; Schulz et al, 1989) and the British National Formulary.

The patients spent a total of 200 weeks on a psychiatric ICU. In examining the relationship between prescribing and clinical and demographic measures, each week of prescribing was considered separately $(n=200)$. Statistical analysis using Statistical Package for the Social Sciences used the Kendall tau-rank correlation with the significance level set at $P=0.05$.

\section{Findings}

\section{Neuroleptic use}

Sixty-four patients $(88 \%)$ received neuroleptic medication, with a mean (s.d.) dose of $884 \mathrm{mg}$ (667) chlorpromazine equivalence per day. Depot neuroleptic medication was received by $20(27 \%)$ patients. Zuclopenthixol acetate was given to seven patients. Four patients were started on clozapine and six patients on risperidone. Twenty-six (36\%) patients received more than one neuroleptic at any time in their admission. At the time of discharge from psychiatric ICUs only $11(15 \%)$ patients were receiving more than one neuroleptic.

\section{High-dose antipsychotic use}

Thirteen patients received $>1200 \mathrm{mg}$ chlorpromazine equivalence per day for at least one week of their admission. Their mean maximal neuroleptic dose was $2024 \mathrm{mg}$ chlorpromazine equivalence per day (s.d. $752 \mathrm{mg}$ chlorpromazine equivalence per day) and the mean neuroleptic dose on their discharge from the psychiatric ICU was $1324 \mathrm{mg}$ chlorpromazine equivalence per day.

Three of these patients were successfully started on clozapine, and one patient started risperidone leading to improved mental state, a reduction in neuroleptic dose and transfer from the psychiatric ICU. Four patients received a combination of a typical neuroleptic with one of the adjunctive therapies recommended in the
College report (Thompson, 1994). One patient responded to the addition of carbamazepine. One patient responded to the addition of lithium and another to the addition of lithium and 10 bilateral electroconvulsive therapy (ECT) treatments. One patient received a combination of lorazepam and a typical neuroleptic.

Two patients were transferred to a forensic medium secure unit. They received maximal neuroleptic doses of 4217 and $1871 \mathrm{mg}$ chlorpromazine equivalence per day on the psychiatric ICU, although at transfer these patients were both receiving $1200 \mathrm{mg}$ chlorpromazine equivalence per day. Three patients were treated with high doses of a single high-potency neuroleptic (haloperidol, flupenthixol) with no use of adjunctive treatments. All had short admissions (less than two weeks) to the psychiatric ICU.

\section{Use of other medication}

Benzodiazepines, usually lorazepam, were received by 25 patients (34\%). Four patients were prescribed carbamazepine. Nine patients received lithium. One patient received a total of 10 ECT treatments. Twelve patients (16\%) received regular anticholinergic medication during their admission. A further 15 patients received at least one dose of an anticholinergic. Fortysix patients $(63 \%)$ received no anticholinergic medication.

\section{Correlates of neuroleptic use}

There was a significant positive correlation between neuroleptic use, and the maximal symptom rating applied to all weeks of each admission $(r=0.17, n=200, P<0.001)$, the number of past psychiatric admissions ( $r=0.364$, $n=200, P<0.001)$, and a past history of violence $(r=0.25$, d.f. $=200, P<0.001)$. There was no significant positive correlation between neuroleptic use and the number of violent incidents in each week $(r=0.11, n=200, P>0.05)$.

\section{Violent incidents}

There were 84 recorded violent incidents involving 27 patients. Eighteen incidents involved physical aggression directed at objects on the ward; three of these resulting in significant damage. There were 54 incidents of aggression to other people, with 28 involving physical assault, 11 of these resulting in at least moderate injury. Patients were placed in a locked seclusion room after 41 incidents. After a further 27 incidents patients were given a period of 'time out' in an unlocked room. Intramuscular medication was given after 33 and oral medication in a further 21 of these incidents to the patient involved. 


\section{Comment}

This study prospectively documented neuroleptic use on a psychiatric ICU. It is the first such study we know of undertaken with the intention of adopting strategies advocated in the College consensus statement on high-dose neuroleptic use (Thompson, 1994). Data on length of stay and violent incidents suggest that the shortterm management of patients was not adversely affected.

The use of $>1200 \mathrm{mg}$ chlorpromazine equivalence per day for $13(18 \%)$ patients represents a smaller proportion of patients than the twothirds of patients on a psychiatric ICU receiving high-dose neuroleptic medication in a recent retrospective survey (Hillam \& Evans, 1996). The consensus statement accepts the use of high-dose antipsychotic medication for certain patients in certain situations. The prospective design of our study allowed demonstration of the successful use of alternative treatment strategies recommended in the guidelines, leading to a reduction in neuroleptic dose used for the majority of patients admitted to the unit.

The mean recorded neuroleptic dose of $884 \mathrm{mg}$ chlorpromazine equivalence per day, while lower than the usual definition of high-dose antipsychotic use, is higher than the $300-600 \mathrm{mg}$ chlorpromazine equivalence per day recommended from controlled studies (Van Putten $e$ al, 1990: Rifkin et al, 1991, 1994). However this 'optimal' dose range may not be applicable to all patients as on psychiatric ICU, who are often very unwell and with disturbed behaviour.

Correlation analysis suggested that higherdose neuroleptic medication was used appropriately, being given to patients with more severe illnesses, rather than primarily to control disturbed behaviour. It may be that a significant past psychiatric history is simply an additional marker of illness severity. This association may also reflect more cautious treatment in patients without significant past history.

Patients admitted to a psychiatric ICU benefit from adherence to the College consensus on high-dose neuroleptics. Reduced use of either neuroleptic or anticholinergic medication, as well as increased use of alternative treatment strategies are apparent. It is hoped that the guidelines will serve as a framework to further evaluate the therapeutic response to high arousal, aggression and violence.

\section{References}

Hillam, J. \& Evans, C. (1996) Neuroleptic drug use in psychiatric intensive therapy units: problems with complying with the consensus statement. Psychiatric Bulletin, 20, 82-84.

OVERALl, J. E. \& Gorham, D. R. (1962). The Brief Psychiatric Rating Scale. Psychological Reports, 10. 799-812.

Peralta, V., Cuesta. M. J., Caro, F., et al (1994) Neuroleptic dose and schizophrenic symptoms. Acta Psychiatrica Scandinavica, 80, 354-357.

REY, M.-J., SChULZ, P., CostA, C., et al (1989) Guidelines for the dosage of neuroleptics. International Clinical Psychopharmacology. 4, 95-110.

RIFKIN, A., DODDI. S., KARAGI. B., et al (1991) Dosage of haloperidol for schizophrenia. Archives of General Psychiatry. 48, 166-170.

_. - - - et al (1994) Dosage of haloperidol for mania. British Journal of Psychiatry. 165, 113-116.

Schulz, P., REY, M., Dick. P., et al (1989) Guidelines for the dosage of neuroleptics. 2: changing from daily oral to long acting injectable neuroleptics. International Clinical Psychopharmacology. 4, 105-114.

THOMPSON. C. (1994) The use of high dose antipsychotic medication. College consensus statement. British Journal of Psychiatry. 164. 448-458.

VAN PUTten, T., MARDER, S. R. \& MinTz, J. (1990) A controlled dose comparison of haloperidol for newly admitted schizophrenic patients. Archives of General Psychiatry, 47, 754-758.

WALKER, Z. \& SEIFERT, R. (1994) Violent incidents in a psychiatric intensive care unit. British Journal of Psychiatry. 164, 826-828.

WORLD HEALTH ORGANIZATION (1992) The ICD-10 Classification of Mental and Behavioural Disorders. Geneva: WHO.

YUDOFSKY. S. C.. SILvER, J. M., JACKSON, W., et al (1986) The Overt Aggression Scale for the objective rating of verbal and physical aggression. American Journal of Psychiatry, 143, 35-39.

*Hugh Jones, Research Registrar in Psychiatry. Department of Psychiatry, Homerton Hospital, Homerton Row, London E9 6SR; Rachel Jones, Registrar in Psychiatry, and James V. Lucey, Consultant and Senior Lecturer, Department of Psychological Medicine, St Bartholomew's and the Royal London School of Medicine and Dentistry. Queen Mary and Westfield College, University of London

*Correspondence 